Supporting Information

\title{
Installation of thermoswitchable hydrophobic domain into unimer polyion complex for enhanced cellular uptake of siRNA
}

Beob Soo Kim,${ }^{\dagger}$ Shigehito Osawa,,${ }^{\dagger}$ Jongmin Yum,${ }^{\dagger}$ Mitsuru Naito, ${ }^{\S}$ and Kanjiro Miyata ${ }^{*} \uparrow$

$\dagger$ Department of Materials Engineering, Graduate School of Engineering, The University of Tokyo, 7-3-1 Hongo, Bunkyo-ku, Tokyo 113-8656, Japan

$\$$ Department of Applied Chemistry, Faculty of Science, Tokyo University of Science, 1-3 Kagurazaka, Shinjuku-ku, Tokyo 162-8601, Japan

$\S$ Center for Disease Biology and Integrative Medicine, Graduate School of Medicine, The University of Tokyo, 7-3-1 Hongo, Bunkyo-ku, Tokyo 113-0033, Japan

* Corresponding authors

miyata@bmw.t.u-tokyo.ac.jp (K. Miyata)

\section{Experimental Section}

\section{Materials}

Propargyl $p$-toluenesulfonate, 2-ethyl-2-oxazoline (EtOx), and 2- $n$-propyl-2-oxazoline (nPrOx) were purchased from Tokyo Chemical Industry Co., Ltd. (Tokyo, Japan). N-Carboxy anhydride of trifluoroacetyl-L-lysine (Lys(TFA)-NCA) was purchased from Chuo Kaseihin Co., Inc. (Tokyo, Japan). 11-Azido-3,6,9-trioxaundecan-1-amine was purchased from Sigma-Aldrich (St. Louis, MO, USA). Acetonitrile, chlorobenzene, and dimethyl sulfoxide (DMSO) were purchased from Wako Pure Chemical industry (Osaka, Japan). Propargyl $p$-toluenesulfonate and chlorobenzene were used after distillation over phosphorus pentoxide. EtOx, $\mathrm{nPrOx}$, acetonitrile, and DMSO were used after distillation over calcium hydride. Non-labeled siRNA and Alexa Fluor 647 (A647)- 
labeled siRNA were synthesized by Hokkaido System Science Co. Ltd. (Hokkaido, Japan) and Gene Design, Inc. (Osaka, Japan), respectively. The siRNA sequences are as follows: GL3 luciferase siRNA (siLuc): sense, 5'-CUU ACG CUG AGU ACU UCG AdTdT-3' and antisense, 5'-UCG AAG UAC UCA GCG UAA GdTdT-3'; ${ }^{1}$ and scramble siRNA (siScr): sense, $5^{\prime}$-UUC UCC GAA CGU GUC ACG UdTdT-3' and antisense, 5'-ACG UGA CAC GUU CGG AGA AdTdT-3'. ${ }^{2}$ Alexa Fluor 647 was attached to the $5^{\prime}$-end of the sense strand of siLuc (A647-siLuc).

\section{Synthesis of block copolymers}

Poly(2-ethyl-2-oxazoline)- $b$-poly(2-n-propyl-2-oxazoline)- $b$-poly(L-lysine) (PEtOx-PnPrOxPLL) as a triblock copolymer, and PEtOx-PLL as a diblock copolymer were synthesized by a copper-catalyzed click conjugation reaction between alkyne-terminated polyoxazoline and azideterminated PLL (Scheme S1), as previously described. ${ }^{3,4}$

\section{Alkyne-terminated PEtOx-PnPrOx}

Propargyl $p$-toluenesulfonate $(50 \mathrm{mg}, 0.238 \mathrm{mmol}$ ) as an initiator was dissolved in a mixture of acetonitrile $(3 \mathrm{~mL})$ and chlorobenzene $(3 \mathrm{~mL})$. The nPrOx monomer $(1.5 \mathrm{~g}, 13.3 \mathrm{mmol})$ was added to the initiator solution and the mixed solution was stirred under argon at $42{ }^{\circ} \mathrm{C}$ for 6 days. Then, the EtOx monomer ( $3 \mathrm{~g}, 30.3 \mathrm{mmol})$ was added to the polymerization mixture and further stirred under argon at $42{ }^{\circ} \mathrm{C}$ for 6 days. The reaction solution was dialyzed against methanol and deionized water, and freeze-dried to recover as a white powder (yield: $65 \%$ ).

\section{Azide-terminated PLL}

As an initiator, 11-azido-3,6,9-trioxaundecan-1-amine (20 mg, $0.09 \mathrm{mmol})$ in DMSO (1 mL) was added to the Lys(TFA)-NCA $(1 \mathrm{~g}, 3.75 \mathrm{mmol})$ in DMSO $(10 \mathrm{~mL})$, and stirred under argon at $35{ }^{\circ} \mathrm{C}$ for 2 days. The reaction solution was dialyzed against deionized water, and freeze-dried (yield: 78\%). The obtained sample was dissolved in mixture of methanol $(100 \mathrm{~mL})$ and $0.5 \mathrm{~N}$ $\mathrm{NaOH}(20 \mathrm{~mL})$, and stirred $40{ }^{\circ} \mathrm{C}$ for $8 \mathrm{~h}$ for deprotection of TFA. The reaction solution was dialyzed against $0.01 \mathrm{~N} \mathrm{HCl}$ and deionized water, and freeze-dried to recover as a white powder (yield: $88 \%$ ).

\section{PEtOx-PnPrOx-PLL}


Alkyne-terminated PEtOx-PnPrOx (200 mg, $11 \mu \mathrm{mol})$ and azide-terminated PLL (30 mg, 4 $\mu \mathrm{mol})$ were dissolved in deionized water $(5 \mathrm{~mL})$. As catalysts, $\mathrm{CuSO}_{4} \cdot 5 \mathrm{H}_{2} \mathrm{O}(2.8 \mathrm{mg}, 11 \mu \mathrm{mol})$ and sodium ascorbate $(2.2 \mathrm{mg}, 11 \mu \mathrm{mol})$ were added to the polymer solution. The reaction solution was frozen at $-30{ }^{\circ} \mathrm{C}$ overnight and thawed at $4{ }^{\circ} \mathrm{C} .{ }^{5}$ Then, the reaction solution was dialyzed against deionized water, and freeze-dried to recover as a powder. The obtained sample was dispersed in acetone and the precipitate was collected by centrifugation. This process was repeated three times. The obtained precipitate was dialyzed against deionized water, and freeze-dried to recover as a white powder. The final product, PEtOx-PnPrOx-PLL, was characterized by size exclusion chromatography (SEC) and ${ }^{1} \mathrm{H}$ NMR. The SEC was performed using a HPLC system (JASCO, Tokyo, Japan) equipped with a Superdex 75 10/300GL column (GE Healthcare, Chicago, IL, USA). The sample was eluted with $10 \mathrm{mM}$ acetic acid containing $500 \mathrm{mM} \mathrm{NaCl}$ at a flow rate of $0.75 \mathrm{~mL} / \mathrm{min}$ at room temperature (Figure S1a). The ${ }^{1} \mathrm{H}$ NMR spectrum was recorded with ECS400 (JEOL, Tokyo, Japan). The sample was dissolved in $\mathrm{D}_{2} \mathrm{O}$ at $5 \mathrm{mg} / \mathrm{mL}$ and $4{ }^{\circ} \mathrm{C}$ (Figure $\mathrm{S} 1 \mathrm{~b}$ ).

\section{PEtOx-PLL}

As a control, a diblock copolymer, PEtOx-PLL, was synthesized by the similar procedure to prepare the triblock copolymer except adding nPrOx as a monomer. The resulting sample was characterized by SEC (Figure S2a) and ${ }^{1} \mathrm{H}$ NMR (Figure S2b).

\section{Preparation of polyion complexes (PICs)}

Block copolymers (PEtOx-PLL or PEtOx-PnPrOx-PLL) and siRNA were separately dissolved in 10 mM HEPES buffer (pH 7.3; VWR international, Radnor, PA, USA) containing $150 \mathrm{mM} \mathrm{NaCl}$ at a concentration of $1 \mathrm{mg} / \mathrm{mL}$. The polymer solution was mixed with siRNA solution at an equal molar ratio of [primary amines in PLL] to [phosphates in siRNA] at $4{ }^{\circ} \mathrm{C}$. The mixture was incubated at $4{ }^{\circ} \mathrm{C}$ for $20 \mathrm{~min}$, followed by additional incubation at $4{ }^{\circ} \mathrm{C}$ or $37^{\circ} \mathrm{C}$ for $20 \mathrm{~min}$.

\section{Fluorescence correlation spectroscopy (FCS) measurement}

PICs prepared from diblock copolymer or triblock copolymer with A647-siLuc were analyzed by FCS to determine a change in size of PICs at varying concentrations. Sample solutions incubated at $4{ }^{\circ} \mathrm{C}$ or $37{ }^{\circ} \mathrm{C}$ were loaded into 8 -well chamber and immediately measured by FCS using a LSM880 equipped with a C-Apochromat $40 \times$ objective (ZEISS, Oberkochen, Germany). The 
diffusion time $\left(D_{\mathrm{T}}\right)$ of samples was obtained with a sampling time of $10 \mathrm{sec}$ and a repeating time of 12. The diffusion coefficients $\left(D_{\mathrm{C}}\right)$ were calculated from $D_{\mathrm{T}}$ based on a reference of Cy5 maleimide. The hydrodynamic diameter $\left(D_{\mathrm{H}}\right)$ was calculated from $D_{\mathrm{C}}$ based on the StrokesEinstein equation: $D_{\mathrm{H}}=k_{\mathrm{B}} T / 3 \pi \eta D_{\mathrm{C}}\left(k_{\mathrm{B}}\right.$ : Boltzmann's constant, $T$ : absolute temperature, and $\eta$ : dynamic viscosity) (Figure 2a). The temperature-dependent changes in $D_{\mathrm{H}}$ of uPICs were examined for PIC samples that were prepared with $500 \mathrm{nM} \mathrm{A647-siLuc} \mathrm{at} 4{ }^{\circ} \mathrm{C}$ and incubated at the designated temperatures for $20 \mathrm{~min}$ (Figure 3a). The stability of uPICs in serum-containing media was examined for PIC samples that were prepared with $2 \mu \mathrm{M}$ A647-siLuc at $4{ }^{\circ} \mathrm{C}$ and incubated with the designated concentration of FBS at $37^{\circ} \mathrm{C}$ for $1 \mathrm{~h}$. Final concentrations of A647siLuc and FBS were set at $200 \mathrm{nM}$ and $0 \%, 10 \%, 30 \%$, and $50 \%$, respectively (Figure $3 \mathrm{~d}$ ).

\section{Static light scattering (SLS) measurement}

Free triblock copolymers and their PICs prepared with siLuc were analyzed by SLS to determine scattered light intensity (SLI). Each sample was added to a quartz cuvette (ZEN2112; Malvern Instruments, Worcestershire, UK) at $1 \mu \mathrm{M}$ PEtOx-PnPrOx-PLL and their SLI values were measured using Zetasizer Nano-ZS instrument (Malvern Instruments) equipped with a $633 \mathrm{~nm}$ He-

$\mathrm{Ne}$ laser at a scattering angle of $173^{\circ}$. The measurement temperature was increased at $1{ }^{\circ} \mathrm{C} / \mathrm{min}$ to the next designated temperature and equilibrated for $2 \mathrm{~min}$. The SLI was sequentially acquired and normalized to the initial value of each sample (i.e., SLI at $4{ }^{\circ} \mathrm{C}$ ) (Figure $2 \mathrm{~b}$ ).

\section{Dynamic light scattering (DLS) measurement}

PICs prepared from diblock copolymer or triblock copolymer with siLuc (500 nM) were analyzed by DLS to determine number-weighted diameter. Sample solutions were added to a quartz cuvette (ZEN2112) and measured at $37^{\circ} \mathrm{C}$ with a Zetasizer Nano-ZS instrument (Malvern Instruments) equipped with a $633 \mathrm{~nm}$ He-Ne laser and the scattering angle of $173^{\circ}$ (Figure $3 \mathrm{~b}$ ).

\section{Electrophoretic light scattering (ELS) measurement}

uPICs prepared from diblock copolymer or triblock copolymer with siLuc at $4{ }^{\circ} \mathrm{C}$ were analyzed by ELS to determine the zeta potential. Naked siRNA, free polymers, and uPICs (each $10 \mu \mathrm{M}$ and $700 \mu \mathrm{L}$ ) were added to a capillary cuvette (DTS1070, Malvern Instruments) and measured using Zetasizer Nano-ZS instrument (Malvern Instruments) at $4{ }^{\circ} \mathrm{C}$. The zeta potential (ל) was calculated 
from the electrophoretic mobility by the Smoluchowski equation: $\zeta=4 \pi \eta v / \varepsilon(\eta$ : viscosity of the solvent, $v$ : electrophoretic mobility, and $\varepsilon$ : dielectric constant of the solvent) (Figure 3c).”

\section{Cell culture}

Human cervical cancer cells expressing GL3 luciferase (HeLa-Luc; PerkinElmer Inc., Waltham, MA, USA) were cultured in Dulbecco's modified Eagle's medium (DMEM) supplemented with $10 \% \mathrm{FBS}$ and $1 \%$ penicillin/streptomycin in a humidified atmosphere containing $5 \% \mathrm{CO}_{2}$ at 37 ${ }^{\circ} \mathrm{C}$. All medium components were purchased from FUJIFILM Wako Pure Chemical Corporation (Osaka, Japan).

\section{Binding assay}

HeLa-Luc cells were seeded at 10000 per well in 96-well plates and incubated overnight in 10\% FBS-containing media. The cells were kept on ice for 5 min before sample addition. uPIC samples were prepared from A647-siLuc at $4{ }^{\circ} \mathrm{C}$ to a final concentration of $4 \mu \mathrm{M}$ siRNA. Each sample solution was applied to the cells cultured in 10\% FBS-containing media with 1:10, 1:20, and 1:40 dilutions. The cells were incubated at room temperature $\left(22^{\circ} \mathrm{C}\right)$ or $37^{\circ} \mathrm{C}$ for $1 \mathrm{~h}$ without light exposure. The cells were washed with cold PBS twice, and fresh PBS was added to the cells. The fluorescence intensity of A647-siLuc was measured using a microplate reader (Spark, Tecan Group Ltd., Männedorf, Switzerland). Results are expressed as mean and standard deviation ( $n=$ 4) (Figure 4a).

\section{Confocal laser scanning microscopic (CLSM) observation}

HeLa-Luc cells were seeded at 10000 per well in 8-well Lab-Tek chambers and incubated overnight in $10 \%$ FBS-containing media. uPIC samples were prepared from A647-siLuc at $4{ }^{\circ} \mathrm{C}$ to a final concentration of $4 \mu \mathrm{M}$ siRNA. Each sample solution was applied to the cells cultured in 10\% FBS-containing media at $400 \mathrm{nM}$ A647-siLuc. After 2, 6, and $24 \mathrm{~h}$ incubation, the cell nuclei and cell membrane were stained with Hoechst 33342 (Dojindo, Kumamoto, Japan) for 5 min and CellBrite $^{\mathrm{TM}}$ Green (Biotium, Fremont, CA) for $20 \mathrm{~min}$, respectively. The cells were washed with PBS twice to remove extracellular PICs and fluorescent dyes. Then, fresh medium was added to the cells. The CLSM images were obtained by LSM 780 equipped with a C-Apochromat 40× objective (ZEISS). Excitation wavelengths were set at $633 \mathrm{~nm}$ (He-Ne laser), $488 \mathrm{~nm}$ (Ar laser), 
and $405 \mathrm{~nm}$ (Diode laser) for A647-siLuc, CellBrite ${ }^{\mathrm{TM}}$ Green, and Hoechst 33342, respectively (Figure 4b, S3, and S4). The fluorescence intensities of A647-siLuc localized at the cellular periphery and in the cytoplasm were determined using ImageJ software. The obtained fluorescence intensities were normalized to that at the periphery of cells treated with T-uPICs for $2 \mathrm{~h}$ to calculate a relative localization ratio (Figure $4 \mathrm{c}$ ).

\section{Luciferase assay}

HeLa-Luc cells were seeded at 50000 per well in 24-well plates and incubated overnight in 10\% FBS-containing media. UPIC samples were prepared from siLuc or siScr as a control siRNA at 4 ${ }^{\circ} \mathrm{C}$ to a final concentration of $4 \mu \mathrm{M}$ siRNA. Each sample solution was applied to the cells cultured in $10 \%$ FBS-containing media at 100, 200, and $400 \mathrm{nM}$ siRNA. After $48 \mathrm{~h}$ incubation at $37{ }^{\circ} \mathrm{C}$, the cells were lysed with passive lysis buffer (Promega Corporation, Madison, WI, USA), followed by a luciferase assay using Luciferase Assay System (Promega) and Mithras LB 940 (Berthold Technologies, Bad Wildbad, Germany). The obtained photoluminescence intensities were normalized to those from the non-treated cells. Results are expressed as mean and standard deviation $(n=4)$ (Figure $4 d)$.

\section{Cytotoxicity}

HeLa-Luc cells were seeded at 10000 per well in 96-well plates and incubated overnight in 10\% FBS-containing media. uPIC samples were prepared from triblock copolymer and siScr at $4{ }^{\circ} \mathrm{C}$ to a final concentration of $4 \mu \mathrm{M}$ siRNA. Each sample solution was applied to the cells cultured in 10\% FBS-containing media at 100, 200, and $400 \mathrm{nM}$ siRNA. After $48 \mathrm{~h}$ incubation, the cell viability was determined using Cell Counting Kit-8 (Dojindo) according to the manufacturer's protocol. The absorbance at $440 \mathrm{~nm}$ was measured with Tecan Spark and normalized to that obtained from non-treated cells. Results are expressed as mean and standard deviation $(\mathrm{n}=4)$ (Figure 4e).

\section{Statistical analysis}

The comparison among groups was performed by a one-way ANOVA with post-hoc test. Differences were considered statistically significant when $p<0.05$. 


\section{REFERENCES}

1. Zou, J., Marjanovic, J., Kisseleva, M. V., Wilson, M., and Majerus, P.W. (2007) Type I phosphatidylinositol-4,5- bisphosphate 4-phosphatase regulates stress-induced apoptosis. Proc. Natl. Acad. Sci. U. S. A. 104, 16834-16839.

2. Zhang, R., Wu, Y., Zhao, M., Liu, C., Zhou, L., Shen, S., Liao, S., Yang, K., Li, Q., and Wan, H. (2009) Role of HIF-1alpha in the regulation ACE and ACE2 expression in hypoxic human pulmonary artery smooth muscle cells. Am. J. Physiol. Lung Cell. Mol. Physiol. 297, L631L640.

3. Osawa, S., Osada, K., Hiki, S., Dirisala, A., Ishii, T., and Kataoka, K. (2016) Polyplex micelles with double-protective compartments of hydrophilic shell and thermoswitchable palisade of poly(oxazoline)-based block copolymers for promoted gene transfection. Biomacromolecules 17, 354-361.

4. Kim, B. S., Kim, H. J., Osawa, S., Hayashi, K., Toh, K., Naito, M., Min, H. S., Yi, Y., Kwon, I. C., Kataoka, K., et al. (2019) Dually stabilized triblock copolymer micelles with hydrophilic shell and hydrophobic interlayer for systemic antisense oligonucleotide delivery to solid tumor. ACS Biomater. Sci. Eng. 5, 5770-5780.

5. Takemoto, H., Miyata, K., Ishii, T., Hattori, S., Osawa, S., Nishiyama, N., and Kataoka, K. (2012) Accelerated polymer-polymer click conjugation by freeze-thaw treatment. Bioconjugate Chem. 23, 1503-1506. 


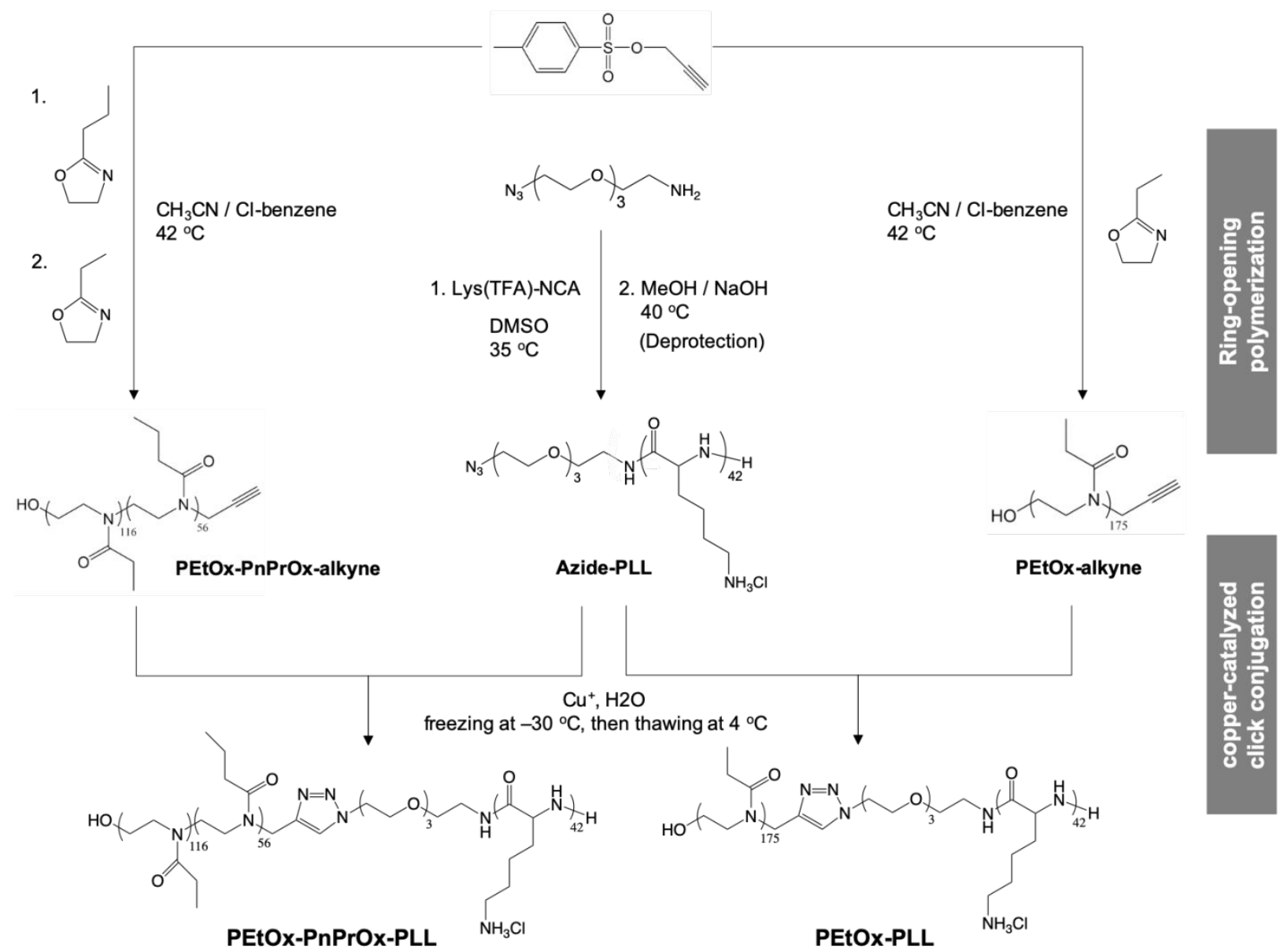

Scheme S1. Synthetic routes of PEtOx-PnPrOx-PLL and PEtOx-PLL. 
(a)

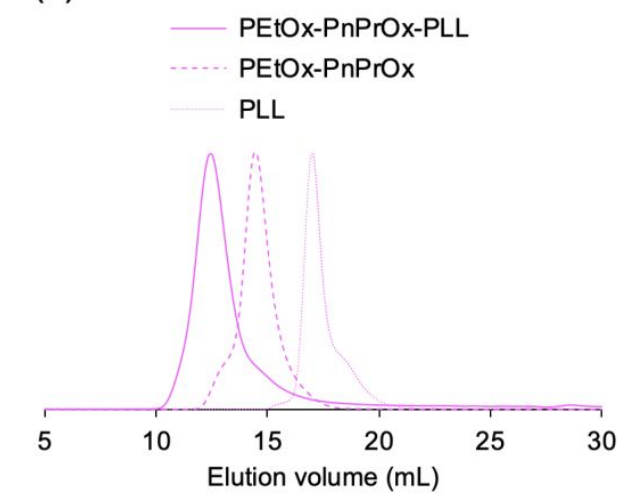

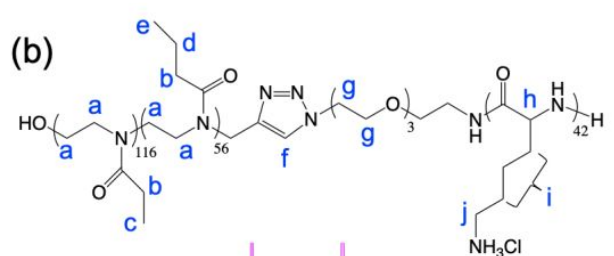

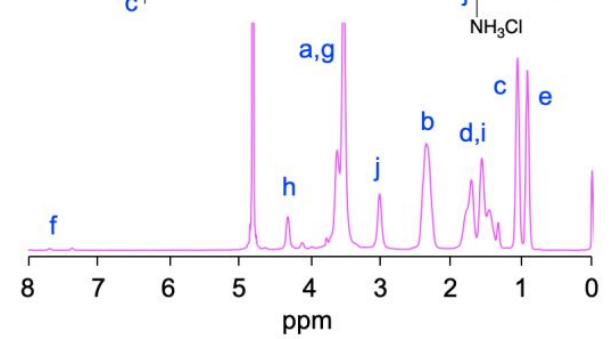

Figure S1. Characterization of PEtOx-PnPrOx-PLL prepared from PEtOx-PnPrOx and PLL. (a) SEC profile (column: Superdex 75 10/300 GL, eluent: $10 \mathrm{mM}$ acetic acid containing $500 \mathrm{mM}$ $\mathrm{NaCl}$, and detector: $\mathrm{UV}$ at $220 \mathrm{~nm}$ ). (b) $1 \mathrm{H}$ NMR spectrum (polymer concentration: $5 \mathrm{mg} / \mathrm{mL}$, solvent: $\mathrm{D}_{2} \mathrm{O}$, temperature: $4{ }^{\circ} \mathrm{C}$, a,g: $700 \mathrm{H}$, b: $244 \mathrm{H}$, c: $348 \mathrm{H}$, d,i: $364 \mathrm{H}$, e: $168 \mathrm{H}$, f: $1 \mathrm{H}, \mathrm{h}: 42 \mathrm{H}$, and $\mathrm{j}: 84 \mathrm{H})$.

(a)

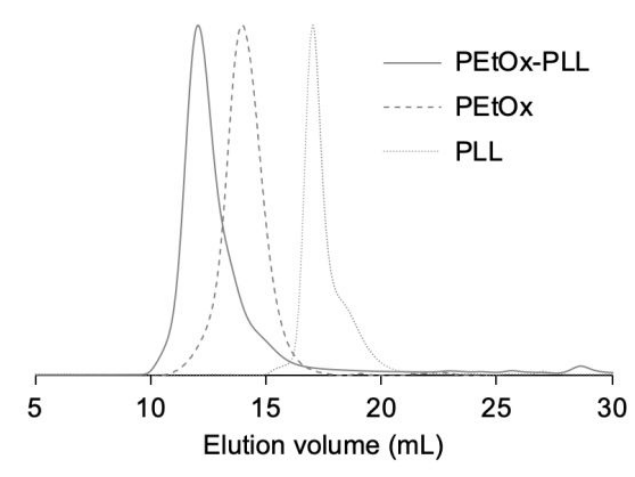

(b)
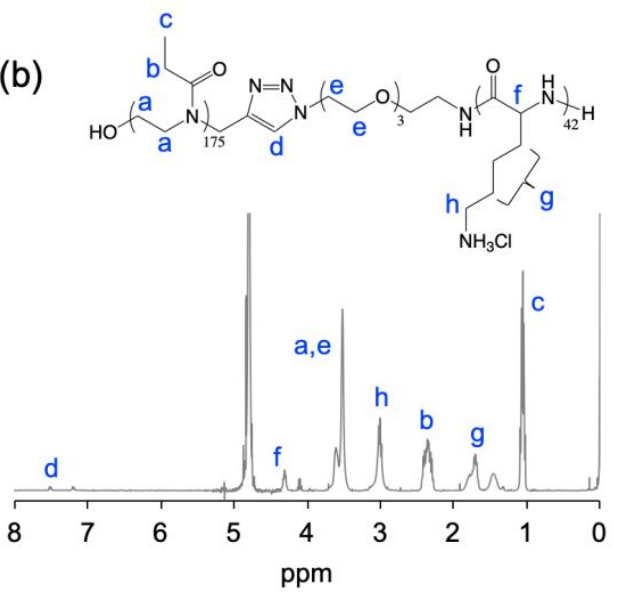

Figure S2. Characterization of PEtOx-PLL prepared from PEtOx and PLL. (a) SEC profile (column: Superdex 75 10/300 GL, eluent: $10 \mathrm{mM}$ acetic acid containing $500 \mathrm{mM} \mathrm{NaCl}$, and detector: UV at $220 \mathrm{~nm}$ ). (b) ${ }^{1} \mathrm{H}$ NMR spectrum (polymer concentration: $5 \mathrm{mg} / \mathrm{mL}$, solvent: $\mathrm{D}_{2} \mathrm{O}$, temperature: $25^{\circ} \mathrm{C}$, a,e: $712 \mathrm{H}$, b: $350 \mathrm{H}$, c: $525 \mathrm{H}, \mathrm{d}: 1 \mathrm{H}, \mathrm{f}: 42 \mathrm{H}, \mathrm{g}: 252 \mathrm{H}$, and h: $84 \mathrm{H}$ ). 


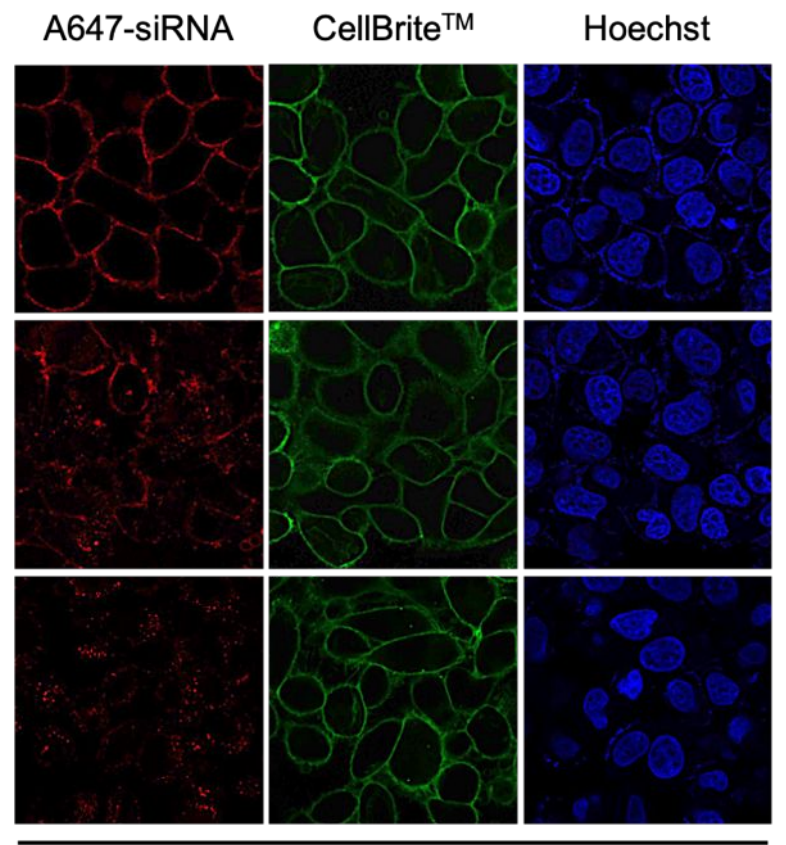

T-UPIC

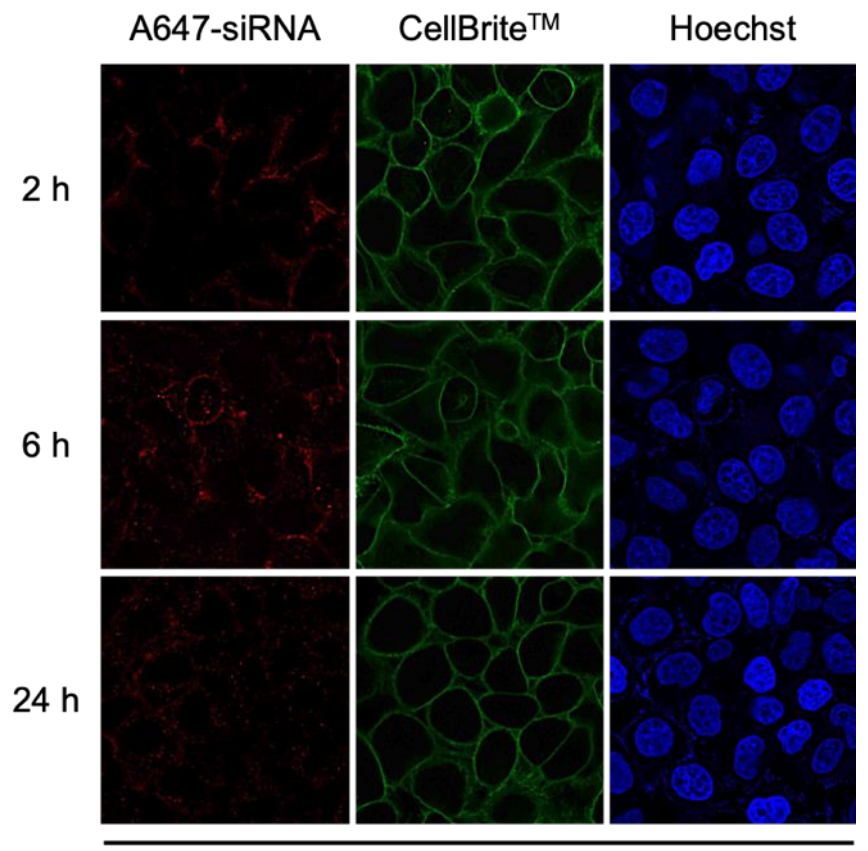

D-uPIC

Figure S3. Unmerged CLSM images of HeLa-Luc cells treated with T-uPICs or D-uPICs (400 nM A647-siLuc) at $37^{\circ} \mathrm{C}$ for 2,6 , and $24 \mathrm{~h}$.
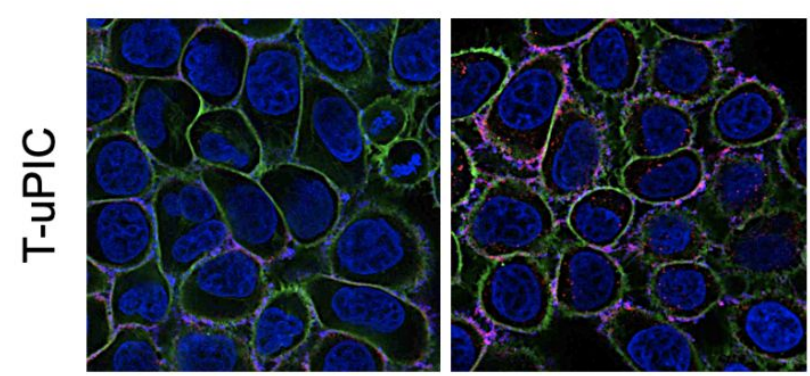

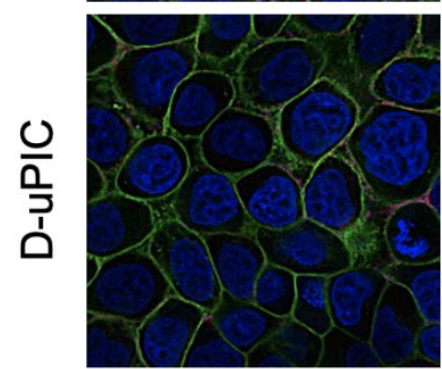

$22^{\circ} \mathrm{C}$

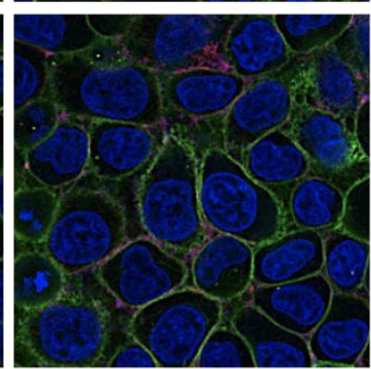

$37^{\circ} \mathrm{C}$

Figure S4. CLSM images of HeLa-Luc cells treated with T-uPICs or D-uPICs (400 nM A647siLuc) for $2 \mathrm{~h}$ at $22^{\circ} \mathrm{C}$ or $37^{\circ} \mathrm{C}$. Nuclei, cell membrane, and A647-siLuc are shown in blue, green, and red, respectively. 